\title{
Psicologia e Acupuntura: Primeiras Aproximações
}

Psychology and acupuncture: The first approaches

Celia Vectore

Universidade Federal de Uberlândia

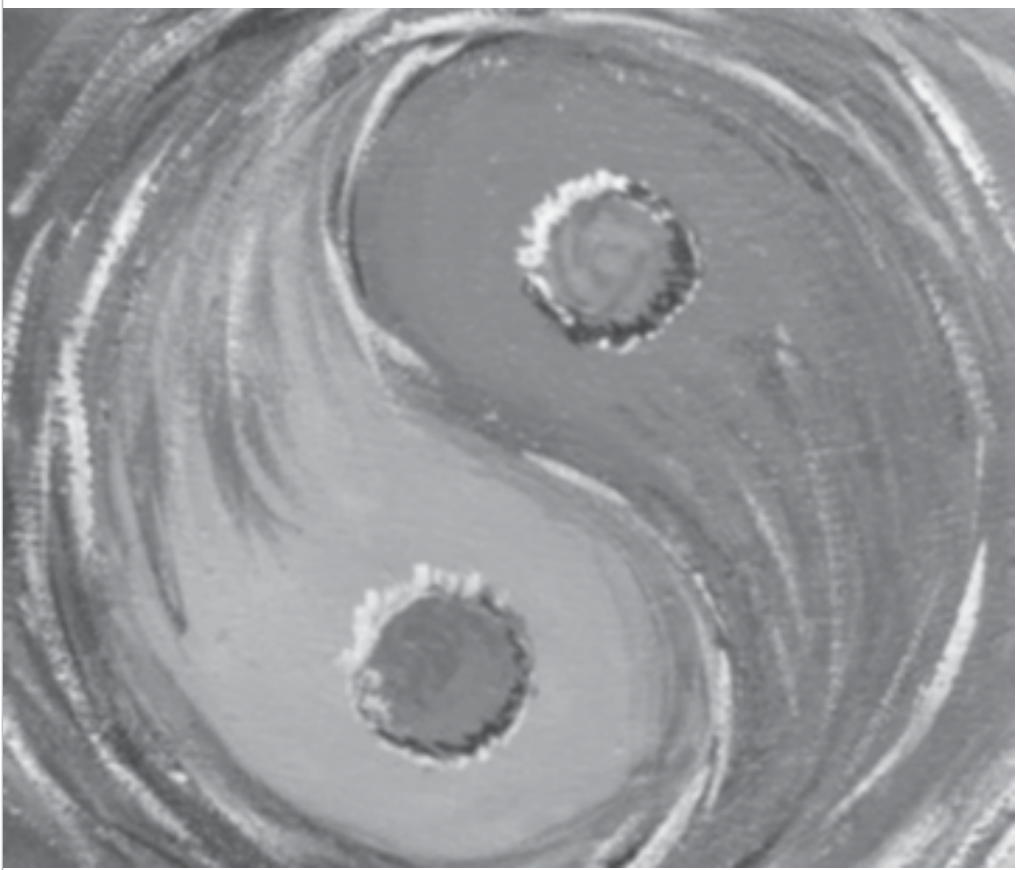




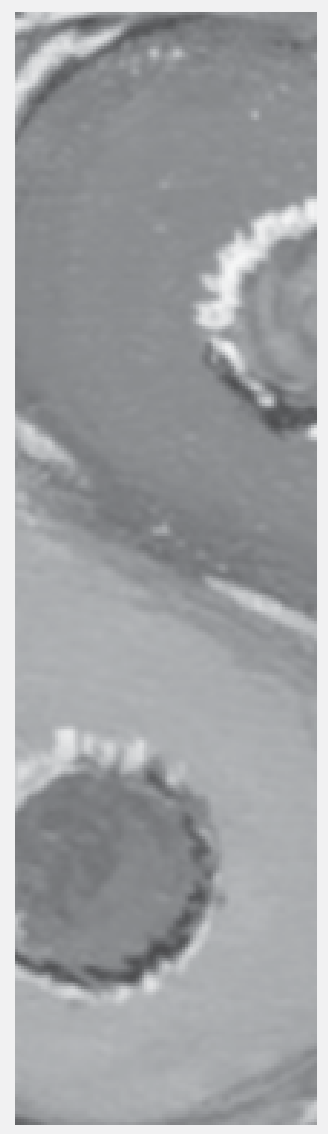

Resumo:Trata-se de um estudo teórico buscando identificar as possibilidades de utilização da prática da acupuntura pelos psicólogos, haja vista a Resolução $n^{\circ} 05 / 02$, do Conselho Federal de Psicologia, que aponta tal técnica como um instrumento do profissional de Psicologia. O trabalho apresenta os principais conceitos que embasam a acupuntura, considerando a sua inserção na medicina tradicional chinesa e na filosofia taoísta, além de fazer uma revisão acurada dos trabalhos científicos que vêm sendo produzidos em diferentes países, oportunizando estudos que mostram a pertinência do conhecimento da acupuntura no tratamento das patologias mentais.

Palavras-chave: acupuntura, patologias mentais, tratamento, Psicologia.

Abstract:This work is a theoretical study searching to identify the possibilities of the use of acupuncture by psychologists, as the Resolution $n^{\circ} 05 / 02$ of the Federal Counsel of Psychology (Conselho Federal de Psicologia-CFP) determines that this technique is an instrument of the professional of Psychology. This study also presents the main concepts that acupuncture is based on, considering its insertion in the Chinese traditional medicine and the taoist philosophy. An accurate revision of the scientific work that has been produced in different countries, carrying out studies that show the relevance of the knowledge of acupuncture in the treatment of the available mental pathologies is also presented.

Key Words: acupuncture, mental pathologies, treatment, Psychology.
Em nenhum momento da história da humanidade a busca pela integração corpo e mente se fez tão presente, como atesta, em escala mundial, a avalanche de literatura sobre alternativas terapêuticas, buscando proporcionar melhor qualidade de vida.

Embora a preocupação por uma saúde integral e harmônica, conforme definido pela Organização Mundial de Saúde, ou seja, o completo bem-estar - físico, psíquico e social e não simplesmente a ausência de sintomas seja tão antiga quanto o homem, o terceiro milênio parece ter-se iniciado com a esperança e com o desejo de se viver mais, porém de forma digna, independente e sem as contínuas mazelas que acometem o ser humano ao longo de seu desenvolvimento.

É evidente que proporcionar saúde física e mental constitui uma tarefa bastante árdua, em virtude das inúmeras variáveis presentes na determinação de melhor condição de vida à população, como o acesso à informação, à educação, às boas condições de moradia e outras que sempre fazem parte das promessas políticas e que infelizmente, em nosso meio, são pouco cumpridas.

A despeito dos inegáveis avanços da ciência em todas as áreas do conhecimento, onde os estudos têm propiciado maior expectativa de 
vida humana na maior parte das culturas, a falta de saúde tanto física quanto mental é ainda um dos problemas que insistem em desafiar os estudiosos, os especialistas e os responsáveis por políticas públicas na busca de soluções eficazes e eficientes, capazes de serem implementadas para um grande número de pessoas.

Nesse sentido, os conhecimentos oriundos da Psicologia, dentro das mais diversas ramificações teóricas que compõem tal ciência, muito têm contribuído ao demonstrar a íntima relação existente entre mente e corpo e, na seqüência, a relação entre algumas perturbações orgânicas e os aspectos de natureza emocional, subjetiva, do indivíduo, nas assim denominadas doenças psicossomáticas, isto é, doenças que, embora apresentem sintomas físicos, têm causa nos comprometimentos mentais.

Por outro lado, a utilização da acupuntura, técnica milenar da medicina chinesa, tem despertado interesse nos mais diversos pesquisadores ocidentais e, entre eles, nos profissionais da Psicologia, em virtude da sua ênfase numa visão holística e integradora do ser humano, ou seja, considerando-o parte indissociável do universo, buscando, desse modo, um modelo científico baseado na interação do homem com os fenômenos da natureza.

A acupuntura é uma especialidade que foi desenvolvida na China há mais de cinco mil anos e, com a moxibustão, o qi gong e a fitoterapia, compõe a medicina tradicional chinesa; visa a prevenir e tratar as doenças através do equilíbrio das energias circulantes no corpo, pois acredita-se que um organismo equilibrado não adoece.

Baseia-se na existência de acupontos, distribuídos ao longo de doze linhas imaginárias, chamadas meridianos (coração, fígado, baço-pâncreas, pulmão, estômago, rim, circulação-sexo, intestino delgado, vesícula biliar, intestino grosso, bexiga e triplo aquecedor), que percorrem o corpo no sentido vertical, formando pares simétricos nas faces dorsal e ventral da superfície corporal, os quais, devidamente estimulados, normalmente, por agulhas, são capazes de promover uma série de benefícios à saúde do indivíduo.

Segundo a abordagem bioenergética, da qual faz parte a acupuntura, a doença não é um fenômeno alienado no corpo. A acupuntura compreende a integração mente-corpo como um círculo de interação entre os sistemas internos e os aspectos emocionais, passível de ser concretizado através de três tesouros, ou seja, a Essência, o Qi e a Mente.

A Organização Mundial da Saúde (OMS) reconhece o uso da acupuntura para vários tipos de patologias, como, por exemplo, enxaquecas, problemas gastro-intestinais, alergias e dores diversas. Além disso, vários estudos têm demonstrado que a acupuntura apresenta uma influência profunda sobre os problemas emocionais e mentais, sendo recomendável a combinação dessa técnica com outras psicoterápicas.

Desse modo, é interessante que o psicólogo possa conhecer os pressupostos básicos da acupuntura, um dos recursos terapêuticos utilizados pela milenar medicina tradicional chinesa que, por meio de um profundo conhecimento filosófico e de ricas alegorias, demonstra a importância da visão holística, onde o homem e a natureza se encontram interligados ao universo, contrapondo-se à excessiva mecanização e racionalidade do paradigma cartesiano-newtoniano.

Assim, o objetivo do presente artigo é introduzir os pressupostos básicos da acupuntura bem como o estado da arte dos estudos voltados 
para a interação entre Psicologia e acupuntura, buscando identificar as possibilidades de utilização da prática da acupuntura pelos psicólogos, haja vista a Resolução n ${ }^{\circ} 05 / 02$, do Conselho Federal de Psicologia, que aponta tal técnica como um instrumento do profissional de Psicologia.

\section{Um pouco de história}

A acupuntura, conforme anteriormente especificado, está inserida no conjunto de técnicas relativas à medicina tradicional chinesa (MTC), que busca compreender e tratar as doenças a partir de uma visão integradora entre o corpo e a mente. A primeira informação sobre a técnica veio através de uma coleção de manuscritos chineses do século XVIII a.C. - O Nei Jing (Nei Ching), comumente conhecido como o Tratado do Imperador Amarelo, uma figura mitológica que conversa com os seus médicos, revelando os dogmas da medicina chinesa.

Especificamente, a acupuntura começou a ser aplicada e estudada pela Medicina ocidental na década dos anos setenta, embora os primeiros relatos dessa técnica no Ocidente tenham sido feitos por missionários que viajaram ao Oriente nos séculos XII e XIII.

Segundo Sabbatini (2003), a ocidentalização da acupuntura ocorreu "quando a filosofia oriental foi apropriada pelos hippies e outros movimentos sociais alternativos em rebeldia contra o 'establishment' americano responsável pela Guerra do Vietnã”. Além disso, foi impulsionada pelo fato ocorrido em 1971, durante a visita do então presidente norteamericano Richard Nixon à China, quando dois cirurgiões americanos assistiram à extirpação de um ovário com anestesia pela acupuntura, apenas.

Atualmente, a prática existe no mundo inteiro e é crescente sua procura, em virtude, principalmente, da simplicidade da técnica, da sua eficácia, rapidez e busca do equilíbrio biopsíquico dos pacientes. Por outro lado, os fatores apontados pela MTC como causadores das patologias (clima, emoções, dieta etc) se aplicam a qualquer sociedade, bem como os sentimentos de fúria, tristeza, dor e preocupação, são básicos em qualquer ser humano.

No Brasil, a técnica começou a ser praticada em 1810, pelos imigrantes chineses, e, mais tarde, em 1908, pelos japoneses. No início da década de cinqüenta, a acupuntura foi introduzida no país por Frederico Spaeth, que foi um dos fundadores do Instituto Brasileiro de Acupuntura - IBRA, atualmente denominado Associação Brasileira de Acupuntura - ABA.

Em relação às bases científicas da acupuntura, tem-se que, segundo princípios anatômicos e fisiológicos, o estímulo da acupuntura obedece a impulsos nervosos, considerando que a maior parte dos pontos de inserção localiza-se nas proximidades dos nervos periféricos. Outras teorias apontam uma natureza humoral da acupuntura.

\section{Yin-Yang}

O conceito do Yin-Yang é um dos mais importantes na medicina tradicional chinesa. Baseia-se na existência do Tao como força divina que dá origem ao Universo e que imprime leis e lógica à energia universal, permitindo que ela se organize, criando os planetas e as estrelas, os elementos da natureza e, por fim, a vida.

O Tao organizou as forças do universo criando as chamadas "polaridades universais”, forças opostas, mas complementares, que regulam os padrões de organização na natureza, ou seja, o Yin e o Yang. Essa lógica é, segundo Maciocia (1996), radicalmente diferente da lógica ocidental, estruturada na oposição dos contrastes, premissa fundamental da lógica aristotélica. Assim, Yin e Yang representam o
A acupuntura, conforme anteriormente especificado, está inserida no conjunto de técnicas relativas à medicina tradicional chinesa (MTC), que busca compreender e tratar as doenças a partir de uma visão integradora entre o corpo e a mente. 
... "Do Tao surgiram os opostos Yin e Yang. Eles são complementares $e$ interdependentes. Se todo o povo da Terra sabe que bom é bom, isto significa $o$ reconhecimento do mal. Então ser e não ser são interdependentes em crescimento, difícil e fácil são interdependentes em atitude, $e$ alto e baixo são interdependentes em posição"

Lao-Tse apud Botsaris desenvolvimento de todos os fenômenos no universo, sendo o resultado de uma interação de dois estágios opostos que contêm ambos os aspectos, em diferentes graus de manifestação, num movimento cíclico e relativo.

Lao Zi ou Lao-Tse (570 a.C.), um dos principais filósofos chineses e um dos formuladores da doutrina do Tao, escreveu:

... "Do Tao surgiram os opostos Yin e Yang. Eles são complementares e interdependentes. Se todo o povo da Terra sabe que bom é bom, isto significa o reconhecimento do mal. Então ser e não ser são interdependentes em crescimento, difícil e fácil são interdependentes em atitude, e alto e baixo são interdependentes em posição” (Lao-Tse apud Botsaris, 1999, pp.23-4).

É interessante observar que o Yang representa o estado mais rarefeito e imaterial da substância (Céu), e o Yin simboliza o estado mais material e denso (Terra). Desse modo, pode-se acrescentar mais alguns atributos na correspondência Yin-Yang, como:

Yang: produz energia, gera, não substancial, energia, expansão, ascendência, acima, fogo, rapidez, mudança.

Yin: produz forma, cresce, substancial, matéria, contração, descendência, abaixo, água, lentidão, conservação.

\section{Quatro aspectos do relacionamento Yin-Yang}

Oposição do Yin e Yang: contradição que se constitui na força motriz de toda mudança, desenvolvimento e deterioração dos fenômenos. Entretanto, a oposição é relativa, e não absoluta, pois tudo contém a semente do seu oposto, e ser Yin ou Yang é dependente do fenômeno ao qual está relacionado; por exemplo, o clima de São
Paulo é Yin em relação ao clima de Ribeirão Preto, porém é Yang em relação ao da Groelândia.

Interdependência do Yin e Yang: embora sejam opostos, são interdependentes, pois um não pode existir sem o outro; como exemplo, observa-se que não há atividade sem descanso, contração sem expansão, etc.

Consumo mútuo do Yin e do Yang: o Yin e o Yang devem estar em constante equilíbrio; contudo, há quatro estados passíveis de desequilíbrio: (1) preponderância do Yin; (2) preponderância do Yang; (3) debilidade do Yin; (4) debilidade do Yang.

Inter-relacionamento do Yin e Yang: o Yin e o Yang não são estáticos, mas transformam-se mutuamente. Essa mudança acontece somente em determinados estágios do desenvolvimento, como, por exemplo, o verão se transforma em inverno, a vida em morte, etc.

\section{Os Cinco Elementos}

Junto à teoria do Yin-Yang, a teoria dos cinco elementos ou movimentos constitui a base da medicina tradicional chinesa, e foi elaborada pelos filósofos chineses para explicar o comportamento da natureza e dos seres vivos. Há um ciclo de transformação, com ordem específica, chamado de ciclo de geração e de dominância.

“A Madeira corresponde à Primavera, sendo associada ao nascimento; o Fogo corresponde ao Verão e está associado ao crescimento; o Metal corresponde ao Outono, associado à colheita; a Água corresponde ao Inverno e está associada ao armazenamento; a Terra corresponde à estação anterior, associada a transformação” (Maciocia, 1996; p.25).

Seqüência de geração: cada elemento gera o outro, sendo, ao mesmo tempo, gerado. 
Desse modo, a Madeira gera o Fogo, o Fogo gera a Terra, a Terra gera o Metal, o Metal gera a Água e a Água gera a Madeira.

Seqüência do controle: cada elemento controla o outro, ao mesmo tempo que é controlado. Portanto, a Madeira controla a Terra, a Terra controla a Água, a Água controla o Fogo, o Fogo controla o Metal e o Metal controla a Madeira.

Seqüência da lesão: ocorre quando o equilíbrio é afetado, ou seja, a Madeira lesa o Metal, o Metal lesa o Fogo, o Fogo lesa a Água, a Água lesa a Terra e a Terra lesa a Madeira.

Os cinco elementos correspondem às cinco estações da vida na Terra; os seres vivos têm aspectos que se identificam com cada movimento, e a existência da saúde implica a harmonia entre todos os movimentos.

É interessante observar que um dos aspectos mais marcantes da medicina tradicional chinesa é a ressonância entre os fenômenos da Natureza e os do organismo. Algumas das principais correspondências são apresentadas na tabela 1 .

Tabela 1: Principais correspondências dos cinco elementos

\begin{tabular}{l|l|l|l|l|l|}
\hline & Madeira & Fogo & Terra & Metal & Água \\
\hline Ptos Cardeais & Leste & Sul & Centro & Oeste & Norte \\
\hline Estações & Primavera & Verão & 5 estação & Outono & Inverno \\
\hline Clima & Vento & Calor & Umidade & Secura & Frio \\
\hline Cores & Verde & Vermelho & Amarelo & Branco & Preto \\
\hline Sabores & Ácido & Amargo & Doce & Picante & Salgado \\
\hline Movimentos & Nascimento & Crescimento & Transformação & Recepção & Conservação \\
\hline Sentidos & Visão & Tato & Paladar & Olfato & Audição \\
\hline Emoções & Cólera & Prazer & Reflexão & Tristeza & Medo \\
\hline
\end{tabular}

Em virtude dessa interação, o equilíbrio de cada um dos “cinco elementos” depende do equilíbrio das outras funções que, todavia, podem estar em desarmonia, devido a agressões comprometedoras do equilíbrio entre o Yin e o Yang.

Os princípios contidos no Nei Jing (Nei Ching), que sustentam a MTC, sugerem que "não existe doença, mas, sim, doentes”, o que supõe a necessidade de uma visão global e integradora entre todos os sistemas que compõem o organismo vivo.

\section{Os cinco elementos no diagnóstico}

A correspondência entre os cinco elementos e a cor, o sabor, as emoções, os odores, e os sons, entre outros aspectos, é amplamente utilizada no diagnóstico. É interessante lembrar que o diagnóstico, na MTC, tem como objetivo reconhecer e corrigir padrões de desarmonia. Além disso, de acordo com Brewington, Smith e Lipton (1994), o pensamento, nessa medicina, é holográfico, isto é, o todo pode ser reconhecido em cada uma das partes. 
Segundo a medicina tradicional chinesa (MTC), a integração mente-corpo é vista como um círculo de energia e substâncias vitais em constante interação com os sistemas, de modo a formar o organismo. As substâncias vitais são:

Qi: corresponde a todas as funções da energia corporal, representadas pelo funcionamento do metabolismo; é a “raiz do homem” (Nei King). O Qi produz o Sangue, o Qi faz circular o Sangue e o Qi segura o Sangue nos vasos. Botsaris (op. cit.) compara o conceito do Qi aos ensinamentos da física quântica, onde eletricidade e matéria são energias. Os principais tipos de energia corporal são:

"fisiologia humana

é baseada na transformação do Qi. O Qi em condensação forma o corpo material, seno de natureza Yin. O Qi na forma dispersa move-se, sendo de natureza Yang... Se o Qi é transformado adequadamente, movimento, nascimento, crescimento e reprodução podem ocorrer...Se o Qi floresce, há saúde, se débil, há patologia, se é equilibrado, há tranqüilidade, caso se mova na direção errada, há patologia”

Maciocia
Energia nutridora (Yin Qi) - é a energia resultante da alimentação e da respiração combinadas, que circula no sangue, a fim de nutrir os órgãos e tecidos.

Energia de defesa (Wei Qi) - é a energia responsável pelos processos de defesa do organismo, correspondente às ações do sistema imunológico.

Energia do tórax (Zong Qi)- é a energia correspondente ao funcionamento do pulmão e do coração.

- Energia dos alimentos (Jing Qi) - relativa às substâncias absorvidas dos alimentos pelo tubo digestivo.

Energia ancestral (Yuan Qi)- ligada às manifestações dos gens, localizados no DNA das células, regulando o desenvolvimento do embrião até a formação de um ser humano adulto.

Sangue: é formado de fluido corporal, da essência da medula óssea, do Yin Qi, ou energia nutridora, e Wei Qi, ou energia de defesa. Tem como funções: a nutrição, a defesa, a promoção do crescimento, a hidratação e a prevenção de tumores.
Essência ou Jing: é a origem da "energia ancestral”, que representa a expressão dos gens; por isso, vários autores o interpretam como simbolizando o DNA. Segundo a MTC, a essência está localizada no Rim, que a distribui pelo sistema nervoso central e medula óssea, estando presente em todos os órgãos e tecidos para que tenham vitalidade.

Fluidos corpóreos ou Jin Ye: componente análogo ao líquido extracelular da Medicina ocidental. É composto de água e outras substâncias produzidas pelo baço-pâncreas.

Desse modo, segundo Sobrinho (2001), através da boca são introduzidos alimentos no estômago (yin) que, ao serem processados, transformam-se em sangue (Terra) pelo BaçoPâncreas. A seguir, o sangue é encaminhado ao Pulmão, onde será oxigenado (yang). Do Pulmão, o sangue segue para o Rim, onde é filtrado e aquecido pela energia ancestral. Do Rim, o sangue é encaminhado ao Fígado, onde será armazenado e controlado. O Fígado é quem controla a corrente sangüínea em circulação. Por fim, o Coração representa a bomba que impulsiona o sangue energizado para todo o organismo.

Finalizando, pode-se dizer que a

“fisiologia humana é baseada na transformação do Qi. O Qi em condensação forma o corpo material, sendo de natureza Yin. O Qi na forma dispersa move-se, sendo de natureza Yang... Se o Qi é transformado adequadamente, movimento, nascimento, crescimento e reprodução podem ocorrer...Se o Qi floresce, há saúde, se débil, há patologia, se é equilibrado, há tranqüilidade, caso se mova na direção errada, há patologia” (Maciocia, 1996, p.79).

Portanto, a cura ocorre quando o Qi (força vital) do indivíduo é mobilizado e corrigido, de modo a restabelecer o correto fluxo da energia. 


\section{Acupuntura e psiquismo}

Considerando a visão holística adotada pela medicina tradicional chinesa, tem-se que os pensamentos e as emoções influenciam diretamente a força vital, aumentando, ou ao contrário, paralisando o fluxo de energia pelo corpo. Esse processo pode ser considerado uma via de mão-dupla, onde o psiquismo não pode ser separado dos órgãos e vice-versa, isto é, as perturbações psíquicas, relativas às emoções, podem perturbar diretamente os órgãos e as alterações orgânicas podem agir sobre o psiquismo.

Assim, o psiquismo é basicamente Yang, e, como tal, depende da energia Yang oriunda do ar e da luz. Entretanto, deve-se mencionar que tal psiquismo é, por sua vez, alimentado pela força Yin, oriunda dos alimentos e da terra, numa dependência e interpenetração constantes. Considerando que o fluxo do Qi influencia a psique, tem-se que os sentimentos localizados nos órgãos atuam causando insuficiências ou plenitudes.

Sinteticamente, tem-se que:

O Coração, o órgão mais Yang dos órgãos, é a sede da mente; atua sobre a vida intelectual, equilibrando a razão e conservando a energia mental;o BaçoPâncreas atua sobre o consciente, facilitando a concentração do pensamento e a compreensão, principalmente em Matemática; o Rim, o órgão mais Yin, é o gerador de energia; atua sobre os processos de tomada de decisão, conservando a vontade e a vitalidade; o Fígado, considerado a sede das emoções da alma, mantém o livre fluxo da energia do corpo, atuando sobre a ação, a inveja e o ciúme; o Pulmão capta a energia vital, atuando na defesa do organismo e nas perdas afetivas. O vaso-governador e o vaso-concepção atuam sobre a percepção da realidade.
Os sentimentos que causam plenitude, ou seja, excesso de Yang, são, normalmente, identificados pelo descontentamento, pesar, obsessão, preocupação, como também pelo silêncio e pela ociosidade. Os sentimentos que causam insuficiência, ou seja, vazio de Yin, são, normalmente, identificados pela alegria, medo e também fadiga.

Desse modo, tem-se que a acupuntura contempla cinco emoções (alegria, tristeza, reflexão, cólera e medo), sendo o estado de saúde dependente da harmonia entre as cinco emoções; as alterações emocionais levam aos quadros de excesso ou deficiência.

\section{Principais desequilíbrios}

Emoções na MTC:

Fúria: inclui ressentimento, fúria contida, irritabilidade, frustração, ódio, indignação, animosidade ou amargura. Qualquer um desses estados emocionais pode afetar o Fígado e, se persistir ao longo do tempo, pode causar a Estagnação do Qi desse órgão com a manifestação de muitos sintomas na cabeça, como: cefaléia, zumbido, tontura, manchas vermelhas na parte frontal do pescoço, rubor facial, sede, língua vermelha e gosto amargo na boca.Há a possibilidade de se ter também sintomas como submissão, depressão (fúria reprimida - língua vermelha escura e seca) e palidez.

Alegria: deve ser entendida não como um estado saudável de felicidade, mas um excitamento excessivo que pode lesar o Coração, como, por ex., em uma crise de enxaqueca causada por boas notícias repentinas.

- Tristeza: debilita o Pulmão, mas também afeta o Coração. O Pulmão governa o Qi e a tristeza depaupera o Qi, provocando sintomas como dispnéia, cansaço, depressão ou choro, e, nas mulheres, pode provocar amenorréia. 
Preocupação e Abstração: pensar demais, exercer um trabalho mental ou estudo excessivo debilita o Baço e causa cansaço, anorexia e diarréia. A preocupação depaupera o Qi do Baço, paralisando o Qi do Pulmão e provocando sintomas como ansiedade, dispnéia e rigidez nos ombros e pescoço.

Medo: depaupera o Qi do Rim e faz o Qi descender. Nas crianças, situações geradoras de medo e insegurança levam à descida do Qi, podendo provocar a enurese noturna. Em adultos, medo e ansiedade provocam a deficiência do Yin do Rim, levando à sensação de calor na face, sudorese noturna, palpitação, boca e garganta secas.

Choque emocional: suspende o Qi e afeta o Coração e o Rim, causando sintomas como palpitação, dispnéia, insônia, sudorese noturna, boca seca, tontura ou zumbido.

\section{Causas Externas:}

Seis excessos - Vento (primavera), Frio (inverno), Calor (verão), Umidade (fim do verão), Secura (outono) e Fogo (verão).

Outras causas patológicas:

compleição debilitada, excesso de exercícios físicos, excesso de atividade sexual, dieta irregular, trauma, parasitas e venenos e tratamento inadequado.

Jing Luo

Jing Luo (Jing - dirigir, caminhar e Luo - rede) é habitualmente traduzido por meridianos ou canais energéticos que, apesar de invisíveis, são considerados um mecanismo físico, com trajeto definido, marcado por pontos cutâneos sensíveis - os pontos de acupuntura, os quais, ao serem estimulados, podem provocar tanto a sensação de calor quanto de parestesia. São pontos de baixa resistência elétrica na pele. Para as pessoas saudáveis, cada canal energético tem, durante as vinte e quatro horas do dia, um período de duas horas cuja atividade é máxima.

Assim, pode-se dizer que a personalidade, isto é, a organização dos sistemas cognitivo, afetivo e de comportamento do indivíduo socialmente pertinentes, é formada tanto pela adequada função dos órgãos quanto pelas interações sociais vivenciadas pelo sujeito.

Segundo Oyanedel (2002), a apreciação subjetiva dos fatos por parte do indivíduo definirá o órgão em que o sintoma irá manifestar-se. Por exemplo, um indivíduo preocupado consigo mesmo poderá desenvolver uma úlcera gástrica e, se a preocupação for voltada aos outros, o órgão a ser afetado será o baço-pâncreas. A tabela 2 apresenta as alterações nos padrões de equilíbrio.

Tabela 2: Alterações nos padrões de equilíbrio energético.

\begin{tabular}{|l|l|l|l|l|}
\hline Elemento & Equilíbrio & Desequilíbrio & Excesso & Deficiência \\
\hline Terra & Reflexão & Preocupação & Autoritário & Dependência \\
\hline Metal & Serenidade & Ansiedade & Euforia & Insegurança \\
\hline Água & Calma & Apreensão & Imprudência & Medo \\
\hline
\end{tabular}

Segundo Steiner (1990), desde a Antiguidade, já se distinguem os temperamentos sangüíneo, melancólico, colérico e fleumático, os quais podem estar diretamente relacionados aos seguintes órgãos: 
Fleumático: relativo ao baço-pâncreas (I), quando em plenitude, apresenta serenidade e calma excessivas, obsessão, fixação no passado, idéias fixas e sem realizações; o oposto relaciona-se à falta de memória, “branco”, ansiedade (não fica quieto) e angústia.

Sanguíneo: relativo ao pulmão (PRO), quando em plenitude, apresenta excesso de autoestima, agressividade, tristeza, obsessão pelo futuro; o oposto relaciona-se ao medo, à preocupação, à perda do instinto de conservação e dos reflexos de defesa.

Colérico: relativo ao fígado (ROUNN), quando em plenitude, apresenta animação, cólera, ira e hiperatividade; o oposto relaciona-se à falta de imaginação e concatenação de idéias e de capacidade de expressão.

Melancólico: relativo ao rim (TCHE), quando em harmonia, representa a força de vontade, a determinação, a capacidade de execução das intenções, poder de decisão. Em plenitude, apresenta autoritarismo (problemas de próstata, neoplasias) e impulsividade; o oposto relaciona-se ao medo, à indecisão e à angústia.

Reunião dos quatro temperamentos: relativo ao coração (CHENN), representa a razão tanto individual quanto coletiva. Em plenitude, apresenta excitação mental, dificuldade de concentração, alegria exagerada, riso exagerado, histeria; o oposto relaciona-se ao abatimento, à timidez excessiva e à incapacidade de fazer esforços. Quando em harmonia, apresenta-se como a soma de sensibilidade, alegria e poder de decisão.

Um outro modo de se relacionar a acupuntura com o psiquismo é através da pulsologia, ou seja, do diagnóstico realizado de acordo com as pulsações do indivíduo. Segundo Morant (1990), o quarto pulso está relacionado com as características psicológicas oriundas dos órgãos.

\section{Bases científicas da acupuntura}

Mecanismo de ação da acupuntura

Embora os efeitos da acupuntura já tenham sido relatados há milhares de anos, foi apenas no séc. XX que tal técnica começou a ser investigada cientificamente, em virtude do interesse de médicos chineses com formação científica ocidental em buscar explicar o seu mecanismo de ação.

Han Jisheng, fundador do Centro de Pesquisa em Neurociências da Universidade de Beijing (China), descobriu, em 1972, que a acupuntura era capaz de induzir o encéfalo e a medula espinhal a produzir uma ou mais substâncias capazes de modificar o limiar da dor (aumento do nível de serotonina). Paralelamente a tal descoberta, o mapeamento da estrutura molecular da encefalina (analgésico) levou à suposição que a descoberta dos antagonistas mostraria o modo como a acupuntura utilizava os opióides endógenos para suprimir a dor.

Atualmente, o mecanismo de ação da acupuntura já está relativamente desvendado, em virtude da descoberta de que 366 pontos da acupuntura clássica (são conhecidos mais de 2000 pontos) estão relacionados a dois tipos de fibras nervosas, conhecidas como A Delta e C.

Segundo Franceschini Filho (2001), as fibras A Delta são mais superficiais, reagem a estímulos fortes e são ativadas eletricamente com giros rápidos das agulhas, uma média de cinco rotações por segundo, e são usadas, em geral, como pontos de sedação, isto é, têm efeito calmante. Por outro lado, as fibras $\mathrm{C}$ reagem a estímulos mais suaves, em geral, de cerca de duas rotações por segundo, sendo consideradas pontos de tonificação, ou seja, capazes de estimular o organismo. Ao ser estimulada a área de cinco mm sob os pontos (localizados sobre grandes concentrações de terminações nervosas), há
Embora os efeitos da acupuntura já tenham sido relatados há milhares de anos, foi apenas no séc. $X X$ que tal técnica começou a ser investigada cientificamente, em virtude do interesse de médicos chineses com formação científica ocidental em buscar explicar o seu mecanismo de ação. 
o envio do estímulo para o sistema nervoso central. Da medula espinhal, o estímulo vai para uma região denominada formação reticular, localizada no tronco cerebral, atingindo o mesencéfalo, que é a porção do cérebro situada acima do tronco cerebral. A seguir, o feixe nervoso dirige-se para várias regiões do cérebro, em especial para o hipocampo, área responsável pela memória, e para o hipotálamo, área que controla o sistema nervoso central autônomo e o sistema hormonal. Ao realizar o referido trajeto, há a liberação de endorfina pelo cérebro, que é uma espécie de analgésico fabricado pelo próprio organismo. A substância precursora da beta endorfina, a pró-opiome lanocortina, libera o cortisol, que tem ação antinflamatória. Em relação aos efeitos da eletroacupuntura na otimização da analgesia, pesquisadores como Pomeranz e Chiu (1976) observaram que tanto alta como baixa freqüência de estímulos eliminam a dor. Assim, sabe-se que estímulos com freqüência equivalente a até 5 hertz, o que corresponde a cinco rotações da agulha de acupuntura, levam o corpo a produzir encefalina, um analgésico natural. Acima de 100 hertz, os giros das agulhas causam a sensação de formigamento na área e a liberação de dinorfina (substância mais potente que a morfina) na medula espinhal (Han et al, 1991).

Deve-se considerar que a percepção da dor ocorre porque a pele possui receptores específicos para os diversos tipos de estímulos - temperatura, tato e pressão, pela existência de terminações nervosas livres, principais responsáveis pela percepção do estímulo álgico, em virtude da sensibilidade às diferentes substâncias químicas (potássio, histamina, prostaglandinas e outras capazes de ativar a dor). Assim, tem-se, por exemplo, que uma lesão na pele libera potássio, que estimula fortemente as terminações nervosas livres, enviando a mensagem ao tálamo, que a processa e a envia ao córtex cerebral, possibilitando a sensação de dor.
Portanto, o efeito da acupuntura pode ser explicado ao se considerar que a sensação de dor é proporcional à quantidade de potássio liberado nas terminações nervosas. Experimentos introduzindo íons de potássio através da pele, usando corrente elétrica de intensidade crescente, até a produção da dor, tiveram o seu limiar medido tanto sem acupuntura (ficou inalterado após noventa minutos de teste) como com acupuntura, o qual foi aumentando lentamente (atingindo um pico após vinte ou trinta minutos), permanecendo constante até duas horas.

Desse modo, as pesquisas sobre os efeitos da acupuntura têm demonstrado que, estimulando os pontos de acupuntura, ocorre uma reação, que se dá através da liberação de peptídios opióides no sistema nervoso, que têm efeito analgésico, conforme aponta White (2001). A conceituação filosófica da medicina tradicional chinesa pode ajudar ao mostrar que, para haver equilíbrio, é necessária a existência dos opostos, no caso, se há opióides, há também antiopióides, conforme explicita Han Jisheng (cit. p. Jayasuriya, 1995).

\section{Estudos científicos atuais envolvendo a utilização da acupuntura}

Bresler e Kroening (1976) evidenciaram três fatores essenciais na terapia efetiva de acupuntura, que são: (1) as reações imunes e inflamatórias são mobilizadas quando qualquer área da pele é suficientemente estimulada; (2) a estimulação periférica neural ocorre quando pontos de acupuntura são mecanicamente, eletricamente, quimicamente ou termicamente ativados; (3) o componente psicológico é um fator importante no tratamento com acupuntura.

Outros estudos científicos, como o realizado por O’Callaghan e Jordan (2003), têm 
demonstrado uma alta correlação entre os valores pós-modernos e a utilização da medicina complementar e alternativa, em especial, o uso da acupuntura, o que pode sugerir que, cada vez mais, trata-se de uma técnica extremamente atual na sociedade contemporânea, sendo bem-vindos todos os esforços para o estudo científico de tal abordagem, como, por exemplo, a "Arizona Integrative Outcomes Scale” (AIOS), desenvolvida por Bell et al. (2004).

A acupuntura é utilizada com freqüência cada vez maior em crianças com problemas de hiperatividade e déficit de atenção, conforme estudo de Chan, Rappaport e Kemper (2003), muito embora somente $11 \%$ dos pais discutam, com o especialista responsável pela criança, a utilização de tal técnica, o que, segundo os autores, deve suscitar novas pesquisas sobre a eficácia da terapêutica, agregando esses conhecimentos à prática dos profissionais.

O trabalho efetuado por Nayak et al. (2003) mostrou a prevalência do uso da medicina complementar e alternativa em indivíduos com esclerose múltipla. Güthlin, Lange e Walach (2004) apresentaram a evidência do benefício subjetivo de técnicas como a da acupuntura e homeopatia em pacientes portadores de doenças crônicas e MacPherson et al. (2004) mostraram a importância da empatia com o acupunturista na percepção dos resultados alcançados pelos pacientes. É interessante observar que a busca por abordagens alternativas, entre elas a acupuntura, se deve, principalmente, a um desencanto com a medicina convencional e ao desejo de receber um cuidado holístico, ou seja, um tratamento que reconheça a integração entre a mente, o corpo e o espírito. Os autores concluem que as terapias alternativas devem ser estudadas junto à comunidade científica por serem cada vez mais procuradas pelas pessoas.

Weier e Beal (2004) mostraram a relevância das abordagens alternativas em quadros de depressão pós-parto, e um estudo realizado por Manber et al. (2003) apresentou a importância da percepção da própria doença depressiva por um grupo de pacientes tratados pela acupuntura como um fator de predição à aderência ao tratamento, às expectativas e às crenças nas terapias alternativas. O trabalho, embora não visasse especialmente mensurar os efeitos da acupuntura em relação à depressão, mostrou que tal técnica tem sido uma importante aliada em investigações que objetivam conhecer os aspectos psicológicos dos pacientes, relacionados aos diferentes modos de se lidar com as doenças e com a dor.

Pesquisadores gregos, como Fassoulaki et al. (2003), investigaram o efeito da acupressão no ponto “extra 1” por dez minutos e concluíram que houve uma redução nos escores relacionados ao stress verbal quando comparados com a aplicação em um ponto qualquer, efetuada no grupo de controle. $\mathrm{O}$ efeito da inserção de agulhas no ponto "C7” na redução do stress psicológico foi observado por Chan et al. (2003).

Os estudos têm mostrado, ainda, a capacidade da acupuntura em modificar neuroquimicamente o sistema límbico (relacionado às emoções), aumentando o nível de serotonina e sendo, desse modo, indicada para o tratamento de depressões e alguns quadros de esquizofrenia, evitando os efeitos colaterais dos antidepressivos tricíclicos.

Spence et al. (2004) mostraram o aumento da melatonina e a significativa redução da insônia e ansiedade em pacientes tratados com acupuntura durante cinco semanas. Chen, Zhang e Han (2004) evidenciaram que a técnica não invasiva de estimulação magnética transcranial (TMS), cujos princípios são derivados da acupuntura, apresenta efeitos na 
modulação cerebral, sendo, portanto, indicada na pesquisa de doenças neurológicas, distúrbios psiquiátricos e na investigação farmacológica. Um outro estudo utilizando a magnetopuntura, desenvolvido por Li et al. (2003), encontrou evidências fisiológicas de que tal técnica pode reduzir a fadiga mental em motoristas saudáveis.

Por outro lado, Cohen, Rousseau e Carey (2004) apontaram a eficiência da acupuntura na diminuição dos sintomas da menopausa, como as ondas de calor e os distúrbios do sono. Chang, Chung e Rosenwaks (2002) enfatizaram a necessidade de maiores investigações utilizando a técnica da acupuntura ao referirem-se aos estudos envolvendo a utilização do procedimento no tratamento da infertilidade feminina, os quais mostram uma íntima relação entre a liberação de opióides endógenos, particularmente a beta-endorfina após sessões de acupuntura, o que pode ocasionar um impacto no ciclo menstrual através desses neurtopeptídeos.

Tori DeAngelis (2002) afirma que os estudos da psiconeuroimunologia relacionados ao câncer de mama deverão incluir a acupuntura como uma terapia alternativa, capaz de propiciar benefícios aos pacientes.

Em relação ao tratamento da AIDS, não existe consenso sobre a eficácia das terapias alternativas, entretanto, segundo McGuire (2001), cerca de um terço de todos os pacientes fazem uso de abordagens complementares, entre elas a acupuntura. Desse modo, sugere que os pesquisadores devam investigar a eficácia de tais terapias.

Petry (2000) enfatiza a importância de estudos que investiguem a relação entre técnicas alternativas e a redução do stress psicológico em cirurgias.

Estudos brasileiros, como o realizado pelo Ambulatório de Acupuntura Aplicada à
Enxaqueca, do Departamento de Neurologia do Hospital das Clínicas da Unicamp, têm buscado avaliar a eficácia da acupuntura no tratamento da enxaqueca, uma vez que essa doença atinge de 16 a 30 milhões de brasileiros.

A enxaqueca é, geralmente, de origem hereditária, e tem como principal sintoma a dor de cabeça latejante, podendo ser acompanhada por sensibilidade exagerada ao barulho e à luz e sensação de náusea e intolerância a determinados cheiros. Uma das explicações para a enxaqueca é a diminuição da taxa de serotonina do cérebro. Como essa substância tem papel fundamental na percepção dos estímulos dolorosos, sua carência torna as pessoas mais sensíveis à dor. A acupuntura pode complementar o tratamento com medicamentos porque age sobre a dor, liberando os opióides endógenos capazes de suprimi-la. Além disso, trata-se de uma técnica já aceita pela Associação Americana de Medicina e pela Associação Brasileira de Cefaléia como modalidade terapêutica (Maciel cit. p. Klinger, 2002).

\section{Importância do conhecimento da acupuntura pelo profissional de Psicologia: aplicações junto aos transtornos psicológicos}

Em relação às desordens psicológicas, observase que a depressão e suas diferentes manifestações têm sido objeto de investigação de um grande número de profissionais, especialmente da área de saúde, no sentido de melhor compreendê-la, diagnosticá-la e, assim, tratá-la com maior eficácia. A ciência psicológica tem contribuído com diferentes formas de se intervir terapeuticamente no fenômeno depressivo, e, dentre as abordagens mais promissoras, encontra-se a terapia cognitiva, desenvolvida por Aaron Beck (1991). 
Entretanto, ao se considerar as publicações envolvendo as diferentes formas de tratamento das manifestações depressivas, constata-se um grande interesse de pesquisadores da área de Psicologia (Manber et al., 2003; Gallagher et al., 2002; Unutzer et al., 2000; Knaudt et al., 1999; Allen et al., 1998) em investigar a efetividade da terapêutica com acupuntura em relação a tais desordens e a outras, de natureza eminentemente emocional. Eich et al. (1999) mostraram a eficácia da acupuntura no tratamento de episódios depressivos e ansiedade generalizada por meio do agulhamento em pontos como CS 6, C 7 , VC 6, B 62.

White (2000) escreveu um interessante artigo, na prestigiosa revista americana "Professional Psychology: Research and Practice”, intitulado Psicologia e Medicina Complementar e Alternativa. Ao longo do texto, a autora discorre sobre a importância de os psicólogos conhecerem e estudarem cientificamente as abordagens alternativas, como a acupuntura, a homeopatia, a medicina ayurvédica e a naturopatia, pois estatísticas mostram que, em 1997, 42\% da população americana utilizou um tratamento não convencional, gastando cerca de \$21.2 bilhões de dólares com essas práticas, conforme aponta Eisenberg et al. (1998), e, dentre as patologias mais suscetíveis a tais terapêuticas, encontram-se a dor nas costas, a ansiedade, a depressão e as dores de cabeça; há que se considerar que principalmente a ansiedade e a depressão são patologias prioritariamente tratadas por psicólogos. Assim, a referida autora conclui que, possivelmente, os pacientes estão tanto fazendo terapia psicológica junto a uma prática não convencional quanto substituindo a terapia por práticas alternativas.

Contudo, deve-se considerar as dificuldades em se realizar estudos clínicos controlados e aceitos pela comunidade científica utilizandose a acupuntura, pois Lewith e Kenvon (1984) já demonstraram que qualquer agulhamento no corpo produz algum efeito psicológico.

Lanza (1986) mostrou que a combinação da acupuntura com o biofeedback é duas vezes mais efetiva que apenas o biofeedback na redução da ansiedade e tensão muscular.

Outros estudos, como o de Guizhen et al (1998), evidenciaram que a associação da acupuntura na dessensibilização comportamental é claramente superior a qualquer outro procedimento usado no tratamento de pacientes com quadros de ansiedade.

Estudos americanos (Unutzer et al., 2000; Knaudt et al., 1999) têm demonstrado que pessoas com diagnóstico de doenças como síndrome do pânico e depressão são as que mais utilizam técnicas alternativas para o tratamento, muitas vezes sem o conhecimento do terapeuta, embora relatem melhoria em seus sintomas. Existe a dificuldade em avaliar experimentalmente, com métodos quantitativos, tais técnicas, principalmente porque, em muitas dessas técnicas, a força curativa advém da relação entre terapeuta e paciente. Além disso, estudos sérios a respeito da utilização de abordagens alternativas, na maioria das vezes, são publicados em veículos específicos, gozando, normalmente, de menor credibilidade que os jornais científicos para os profissionais da Medicina e da Psicologia.

Bassman e Uellendahl (2003) realizaram um estudo objetivando conhecer como as tendências alternativas eram vistas pelos psicólogos, membros da American Psychological Association (APA). Para tanto, elaboraram um instrumento contendo questões acerca do conhecimento sobre as práticas alternativas bem como do seu uso pelos referidos profissionais, e encaminharam, via correio, as questões para 1000 membros 
da referida associação. É interessante observar que, a despeito do pequeno número de respondentes (202), os psicólogos mostraram uma tendência a reconhecer a importância das técnicas com relação a determinados problemas psicoterápicos, além do desejo de aprender a utilizar algumas dessas técnicas (acupuntura, ervas etc). Entretanto, há a preocupação legal e ética sobre o uso de tais procedimentos.

As autoras do supracitado estudo concluem sobre a pertinência de novos estudos que ampliem o conhecimento sobre a efetividade

É digno de nota que a publicação em inglês de estudos controlados utilizando a acupuntura demonstrou a eficácia da acupuntura em relação à depressão (Luo; Jia e Zhan, 1985; Yang et al., 1994; Hitt, Allen e Schnyer, 1995) e ao abuso de drogas (Meng;

Luo e Halbreich, 2002; Shwatz et al. 1999). das técnicas junto à abordagem psicológica, de modo que venham a respaldar possíveis ações legais.

É importante o investimento em novos estudos, como os que permitiram ao Novo México a possibilidade de incorporar a psicofarmacologia na prática psicológica. $\mathrm{O}$ atual crescimento e demanda por práticas alternativas, além da intensa focalização na espiritualidade, nas sociedades pós-modernas, têm levado os psicólogos a repensarem o seu próprio trabalho, o que, segundo Daw (2002, p.24), “é um exemplo do contínuo crescimento e evolução da Psicologia enquanto uma profissão da saúde“.

É digno de nota que a publicação em inglês de estudos controlados utilizando a acupuntura demonstrou a eficácia da acupuntura em relação à depressão (Luo; Jia e Zhan, 1985; Yang et al., 1994; Hitt, Allen e Schnyer, 1995) e ao abuso de drogas (Meng; Luo e Halbreich, 2002; Shwatz et al. 1999).

Manber et al. (2003) enfatizam que a percepção da doença tem sido descrita na literatura psicológica como um importante prognóstico de saúde, embora tal fator tenha sido pouco contemplado no campo das desordens mentais. Assim, os autores empreenderam um estudo buscando validar o instrumento PDIQ - percepção da depressão pelo paciente, um questionário contendo quatro sub-escalas relativas a: eficácia do eu: reflete a crença do paciente no controle de sua doença; externalização: reflete a crença do paciente de que a sua doença tem causas externas; desesperança/cisão: reflete a crença de que a depressão é uma característica pessoal, havendo pouca esperança de cura; holística: reflete a crença em terapias alternativas.

A importância do instrumento se deve à possibilidade de predizer a aderência do paciente ao tratamento bem como as expectativas, as preferências e a aliança terapêutica, o que pode corroborar os achados do estudo que mostram a importância da relação terapeuta - paciente no sucesso de um tratamento por meio, por exemplo, da acupuntura.

$\mathrm{Na}$ tentativa de fornecer indicadores mais fidedignos em relação à avaliação de crenças na efetividade da acupuntura para o tratamento dos sintomas psiquiátricos, Dennehy, Webb e Suppes (2002) desenvolveram a escala "The Acupuncture Beliefs Scale”, considerando todas as propriedades psicométricas que envolvem a construção de instrumentos de medida.

Dominicus (2002), num interessante estudo sobre os resultados e as expectativas gerados pela acupuntura, concluiu que a percepção dos resultados da acupuntura não está diretamente relacionada ao efeito placebo e às expectativas do paciente, mas, ao contrário, aos fatores referentes ao relacionamento entre terapeuta e paciente. Entretanto, o autor ressalta que o achado deverá ser investigado 
com maiores detalhes, incluindo a construção de instrumentos de medida capazes de mensurarem a qualidade de tal relacionamento. Os estudos devem priorizar tanto a pesquisa qualitativa, considerando a eficiência do tratamento focalizado no paciente, quanto a pesquisa quantitativa com estudos experimentais controlados, de modo a se verificar a eficácia do tratamento.

Wang e Kaing (2001) relataram a eficiência da acupuntura auricular no tratamento das desordens crônicas de ansiedade. Através de procedimento experimental, foi comprovado que a acupuntura auricular no ponto de "relaxamento" diminuiu a ansiedade em voluntários saudáveis. O estudo foi conduzido pela formação de três grupos distintos, sendo que, no grupo 1, era utilizado o ponto Shenmen (porta do espírito), no grupo 2, o de “relaxamento”, e, no grupo 3, um ponto qualquer na orelha.

Em 1998, o Instituto Norte-Americano de Saúde (NIH) organizou uma conferência com diversos especialistas sobre a eficiência da acupuntura. Através do levantamento bibliográfico do período compreendido entre janeiro de 1970 a outubro de 1997 (MEDLINE, Allied and Alternative Medicine, EMBASE E MANTIS), foram encontradas 2302 referências. Os estudos foram analisados considerando a metodologia adotada e os resultados obtidos. Desse modo, tem-se que a acupuntura mostrou ser uma técnica eficaz, entre outras, no tratamento pós-operatório e na redução dos transtornos da quimioterapia. Há evidências da adequação do uso da acupuntura, junto a outras modalidades terapêuticas, nos tratamentos de adição, dor de cabeça e fibromialgia, entre outros.

Vale lembrar que, entre as dificuldades apontadas em estudos dessa natureza, encontra-se o fato de que a colocação das agulhas em qualquer lugar da pele elicia uma resposta biológica, dificultando estudos experimentais que envolvam a eficácia dos pontos (Lewith e Kenvon, op. cit.).

Estudos mostram que a acupuntura pode causar múltiplas respostas biológicas em virtude do papel desempenhado pelos opióides endógenos na analgesia pela acupuntura. A estimulação pela acupuntura pode ativar o hipotálamo e a glândula pituitária, resultando em um largo espectro de efeitos sistêmicos. Há também evidências de alterações nas funções imunológicas deflagradas pela acupuntura. Muitos fatores determinam o resultado terapêutico, como a qualidade do relacionamento e a compatibilidade de crenças entre terapeutapaciente, além do grau de confiança e das expectativas do cliente.

Com base nas preocupações e nos estudos que vêm sendo sistematicamente empreendidos e divulgados na literatura internacional, no que diz respeito principalmente à eficácia e à eficiência de terapêuticas complementares, entre elas, a prática da acupuntura por psicólogos, ressalta-se a necessidade de se ter escolas credenciadas, devidamente fiscalizadas e reconhecidas, para o ensino e a prática da referida técnica terapêutica.

\section{Considerações Finais}

Embora os efeitos da acupuntura já tenham sido relatados há milhares de anos, foi apenas no séc. XX que tal técnica começou a ser investigada cientificamente, em virtude do interesse de médicos chineses com formação científica ocidental em buscar explicar o seu 
mecanismo de ação. Responder a essa questão é uma tarefa hercúlea em virtude das inúmeras variáveis que gravitam em torno de um fenômeno de tal natureza, indo desde fatores de ordem econômica até o nível de formação exigido para a aplicação da técnica, em outras palavras, sobre quem pode efetivamente aplicar a referida técnica, haja vista os recentes embates que, principalmente, o Conselho Federal de Medicina tem travado com outros conselhos profissionais a fim de garantir que a acupuntura seja apenas uma especialidade médica e, assim, só médicos possam prescrevêla e aplicá-la.

Não entrando no mérito de tais discussões, pois nos parecem extremamente carentes de argumentação técnica e teórica, incapazes de justificar a supremacia de um profissional em relação a outro, o certo é que os profissionais de Psicologia devem buscar conhecer o estado da arte em que se encontram as discussões sobre a pertinência da acupuntura na prática psicológica.

Nesse sentido, é digno de nota observar a inédita decisão judicial, proferida pelo Juiz Federal Alexandre Vidigal de Oliveira, em 23 de agosto de 2004, considerando improcedente o pedido do Conselho Federal de Medicina de suspensão da Resolução nº05/2002, editada pelo Conselho Federal de Psicologia, que reconhece o uso da acupuntura como um recurso complementar ao trabalho do psicólogo.

Na tentativa de encaminhar uma reflexão séria sobre a necessidade extremamente atual de que a formação de psicólogo englobe tanto o conhecimento de práticas alternativas quanto sobre o modo como tais práticas podem ser utilizadas na efetivação do trabalho psicológico, a American Psycchology Association (APA) iniciou um processo, organizando seminários educativos sobre a referida temática nas suas reuniões anuais. Além disso, percebese que houve um relativo incentivo de periódicos consagrados internacionalmente em aceitar artigos que trazem à tona tais temáticas, como as aqui levantadas; surpreendeu-nos o grande número de artigos encontrados nas bases Psyinfo e MedPlus sobre estudos envolvendo escalas psicométricas e localização de acupontos para o tratamento dos transtornos mentais, em especial da depressão, entre outros.

Desse modo, no estágio atual dos conhecimentos produzidos, o estudo da acupuntura pode fornecer ao psicólogo novas formas de compreensão e tratamento das perturbações mentais, em especial, as de natureza psicossomática.

Entretanto, ao se analisarem os estudos experimentais desenvolvidos em relação à acupuntura, é possível observar uma certa fragilidade dos resultados obtidos, devido principalmente à qualidade metodológica do trabalho, normalmente evidenciada pela carência de informações a respeito do tipo de agulha utilizado, a profundidade de inserção da mesma e outros dados importantes, como, por exemplo, o tamanho da amostra (na maioria das vezes, é pequeno), o que não permite generalizações. Além disso, a própria técnica de manipulação das agulhas tem sofrido alterações dependendo das culturas onde é aplicada.

A constatação de tais dificuldades, longe de ser um obstáculo intransponível, deve ser encarada como um desafio para os pesquisadores, na busca de um novo paradigma que permita o estudo da acupuntura, de maneira que os seus 
achados possam ter credibilidade junto à comunidade acadêmica. Assim, é imprescindível a realização de pesquisas sobre o efeito da técnica com adequada amostragem, além da utilização de métodos rigorosos que elucidem os princípios e práticas evidenciando o procedimento realizado.

A ciência psicológica, com um pouco mais de um século de existência, em muito já avançou e contribuiu na compreensão dos fatores relacionados às patologias mentais. Entretanto, o preciso diagnóstico das mesmas nem sempre é acompanhado de intervenções capazes de promover o almejado equilíbrio mental do indivíduo, daí a necessidade de se investigar cientificamente a pertinência de novas técnicas.

White (2000) sugere a proveitosa utilização da combinação da Psicologia com técnicas alternativas, enfatizando a necessidade de se promover novos estudos e pesquisas. Mais recentemente, Bassman et al. (2003) sugerem que a adoção de práticas alternativas pelos psicólogos pode representar uma significativa mudança para um paradigma mais holístico, podendo propiciar o incremento e a efetividade na prática profissional desde que as pesquisas continuem a lançar luz sobre a eficácia da técnica.

Em relação especificamente à acupuntura, é interessante destacar que, nos Estados Unidos, trinta e oito Estados mais o Distrito de Columbia licenciam ou regulam a sua prática. Para tanto, o acupunturista deve completar um programa de estudos de três a quatro anos, cujo número de horas-aula é aproximadamente o mesmo exigido para a obtenção de um PhD ou PsyD em Psicologia.

De tudo o que já foi dito, depreende-se que a utilização da acupuntura na prática clínica do profissional de Psicologia é altamente desejável, pois possibilita a exploração dos aspectos psicológicos que podem contribuir para o aparecimento de doenças físicas e também para os fatores fisiológicos que podem estar presentes no desenvolvimento de alterações psicológicas, propiciando uma visão integradora do ser humano.

Assim, a discussão sobre a relevância da associação entre Psicologia e acupuntura é bastante pertinente, sendo, portanto, necessário e desejável um incremento no número de publicações, estudos e pesquisas sobre a eficiência de tal técnica no contexto psicológico. Além disso, deve-se considerar que muitos psicólogos brasileiros já utilizam separadamente a acupuntura em suas práticas profissionais; o Jornal do Conselho Federal de Psicologia, publicado em julho de 2003 (n. 76), trouxe uma nota divulgando a existência da SOBRAPA (Sociedade Brasileira de Psicologia e Acupuntura), que tem empreendido esforços no sentido de cadastrar os psicólogos que são também acupunturistas.

Desse modo, nada mais desejável que a Resolução n05/2002, do Conselho Federal de Psicologia, seja respeitada, salvaguardando aos psicólogos o direito de estudar cientificamente a acupuntura e de utilizá-la em sua prática profissional.

Vale enfatizar que o avanço do CFP, ao admitir a utilização da acupuntura desde que o profissional tenha formação na referida técnica, possibilitará maior produção de conhecimentos e permitirá aos psicólogos brasileiros o direito de acompanhar e de experimentar cientificamente todos os desenvolvimentos da ciência psicológica em relação à acupuntura, os quais vêm ocorrendo em escala mundial, como atestam os trabalhos citados neste estudo. 


\section{Celia Vectore}

Instituto de Psicologia da Universidade Federal de Uberlândia

Rua Delmira Cândida Rodrigues da Cunha, 1279

Uberlândia- MG CEP: 38. 408-208

Tel.: (34) 3219-8695Tel./Fax: (34) 3219-8693

e-mail: vectore@ufu.br

Referências

\section{ALLEN,J.J.B.;SCHNYER, R.N.;HITT,S.K. TheEfficacy of Acupuncture in the Treatment of Major Depression in Women. Psychological Science, 9(5), 1998, pp.397-401. (Ithaca, NY)}

BASSMAN, L. E.,UELLENDAHL, G. Complementary/Alternative Medicine: Ethical, Professional, and Practical Challenges for Psychologists. Professional Psychology: Research and Practice, 34(3), 2003, pp.264-270. (Washington).

BECK, A. T. Cognitive Therapy: a 30-year Retrospective. American Psychologist, 46, 1991, pp.368-375. (Washington).

BECK, J. S. Terapia Cognitiva: Teoria e Prática. Porto Alegre: Artes Médicas, 1997.

BOTSARIS, A.S. Segredos Orientais da Saúde e do Rejuvenescimento. Rio de Janeiro: Record/ Nova Era, 1999.

BRESLER D.E.; KROENING,R. J. Three Essential Factors in Effective Acupunture Therapy. Am J Chin Med., 4(1), 1976, pp.81-6. (Singapore).

BREWINGTON, V.; SMITH, M.; LIPTON, D. Acupuncture as a Detoxification Treatment: an Analysis of Controlled Research. Journal of Substance Abuse Treatment, 11(4), 1994, pp.289-307. (falta cidade).
BUFFINGTON, M. L.; BELL, H. The Five Phases Paradigm and the Myers-Briggs Type Indicator: Correspondence and Therapeutic Applicability. Medical Acupuncture, 10(1), 1998.

Disponível em:_http://www.medicalacupuncture.com/aama_marf/ journal/vol10_1/briggs.html.

Acesso em: 24/11/04.

CALLAHAN, D. The Role of Complementary and Alternative Medicine: Accommodating Pluralism. Washington, DC: Georgetown University Press (Hastings Center Studies in Ethics), 2002, p.214.

CFP REGULAMENTA PRÁTICA DA ACUPUNTURA POR PSICÓLOGOS. Jornal do Federal, Brasília, set./02, p.14.

CHANG, R.; CHUNG, P. H.; ROSENWAKS, Z. Role of Acupuncture in the Treatment of Female Infertility. Fertil Steril. 78(6), 2002, pp.1149-53.

CHEN, J. K. Acupuncture and Herbs in the Treatment of Neurodegenerative Disorders:

Alzheimer's Disease, Stroke and Parkinson's Disease. Medical Acupunture,1(11), 1999. Disponível em: http:// www.medicalacupuncture.com/aama_marf/journal/vol10_1/ 
briggs.html. Acesso em: 24/11/04.

DeANGELIS, T. How do Mind-body Interventions Affect Breast Cancer? APA, 33(6), June,2002. (Washington).

DOMINICUS, W. S. Acupuncture Outcomes, Expectations. American Journal of Public Health, 92(10), 2002, pp.1662-1667. (Washington)

EISENBERG,D.M.;DAVIS, R.B.;ETTNER, S.L.;APPEL, S.; WILKEY,S.; VAN ROMPAY, M.; KESSLER, R. C. Trends in Alternative Medicine use in the United States, 1990-1997. Journal of the American Medical Association, 280, 1998, pp.569-1575. ((Chicago).

FRANCESCHINI FILHO, S. Mecanismo de Ação da Acupuntura na Dor. Revista do Biomédico, 44, 2001, p.22. (São Paulo).

GUIZHEN, L., YUNJUN, Z., LINXIANG, G. , \& AIZHEN, L. Comparative Study of Acupuncture Combined with Behavioral Desensitization for Treatment of Anxiety Neuroses. American Journal of Acupuncture, 26(2/3), 1998, pp.117-120. (Capitola, California).

HALL, C. S.; LINDZEY, G Teorias da Personalidade. São Paulo: EPU, 1973.

HAN, J. S. ; CHEN, X. H. ; SUN, S. L. et al. Effect of Low and Highfrequency TENS on Met-enkephalin-Arg-Phe and Dynorphin a Immunoreactivity in Human Lumbar CSF. Pain, 47, 1991, pp.259-98. (Seattle titulo confirmado).

HITT, S. K.;ALLEN, J.J.B.; SCHNYER, R. N. Acupuncture as a Treatment for Major Depression in Women. Proceedings of the Third Symposium of the Society for Acupuncture Research. Washington, DC: Society for Acupuncture Research, 1995, pp.135-159.

JAYASURIYA, A. AsBases Científicas da Acupuntura. RJ: SOHAKUIN, 1995.

KLINGER, K. HC da Unicamp Usa Acupuntura para Tratar Enxaqueca. Folha de S.Paulo, São Paulo, 03 janeiro, 2002.

LAO-TZU. Tao-Te King. $8^{\mathrm{a}}$ ed. São Paulo: Pensamento, 2000.

LANZA, U. The Contribution of Acupuncture to Clinica Psychotherapy by Means of Biofeedback Training. International Journal of Acupuncture \& Electro-Therapeutics Research, 11(1), 1986, pp.53-57. (falta cidade).

LEWITH, G.; KENYON, J. Psysiological and Psychological Explanations for Mechanism of Acupuncture as a Treatment for Chronic Pain. Social Science Medicine, 19, 1984, pp.1367-1378. (falta cidade).

LINDE, K.; VICKERS. A.;HONDRAS, M.; RIET, G;THORMÄHLEN, J.; BERMAN, B.; MELCHART, D. Systematic Reviews of Complementary Therapies - an Annotated Bibliography. Part 1: Acupuncture. Complement Altern Med.,1(1), 2001, p.3. (falta cidade).

LUO, H.; JIA, Y.; ZHAN, L. Electro-acupuncture v. Amitripyline in the Treatment of Depressive States. Journal of Traditional Chinese Medicine, 5, 1985, pp.3-8. (Beijing).

MANBER, R.; CHAMBERS A. S.; HITT S. K.; MCGAHUEY, C.; DELGADO, P.; ALLEN J. J. B. Patients' Perception of their Depressive Illness. Journal of Psychiatr Res. 37(4), 2003, pp.335-343.(Orlando).

MORANT, S. Acupuntura. São Paulo: Ed. Panamericana, 1990. MYERS, I. B.; MCCAULLEY, M. H. Manual: A Guide to the Development and Use of the Myers-Briggs Type Indicator. Palo Alto, CA: Consulting Psychologists Press, 1985.

NATIONAL INSTITUTES OF HEALTH. Acupuncture-Consensus Conference. JAMA, 280, 1998, pp.1518-1524. (Chicago,)

NAYAK, S.; MATHEIS, R.J.; SCHOENBERGER, N.E.; SHIFLETT, S.C. Use of Unconventional Therapies by Individuals with Multiple Sclerosis. Clin Rehabil., 17(2), 2003, pp.181-191. (London).
NÚCLEODEINFORMAÇÕESSOBREACUPULTURANAINTERNET. Acupuntura e Psiquismo. Disponível em: http:webmaster@Niai.Zzn.Com>. Acesso em: 26/08/03.

O’CALLAGHAN FV, JORDAN N. Postmodern Values, Attitudes and the Use of Complementary Medicine. Complement Ther Med. 11(1), 2003, pp.28-32.

OYANEDEL, J. Acupuntura e Sintomas Psicossomáticos. 2002. Disponível em: <http://www.aesculapius.com>. Acesso em: 23/08/ $\underline{03 .}$

PISANI, F. Mudança de Hábito Alimentar. $2^{\text {a }}$ ed., São Paulo: Robe, 1999.

PODER JUDICIÁRIO (2004). Ação Cautelar; Sentenca n 2289/ 2004. Disponível em: http://psicologiaeacupuntura.com.br/home/ index arquivos/sentenca_CFM.gif. Acesso em 17/09/04.

POMERANZ, B.; CHIU, D. Naloxone Blockade of Acupuncture Analgesia: Endorphin Implicated. Life Science, 19, 1976, pp.1757-62.

REINECKE, M.A.; DATTILIO, F. M.; FREEMAN,A. Terapia Cognitiva com Crianças e Adolescentes. Porto Alegre: Artes Médicas Sul, 1999 .

REQUENA, Y. Acupuntura e Psicologia. São Paulo: Andrei, 1990. RIBEIRO, S. Agulhas, Tatuagens e Neurônios. Viver Mente\&Cérebro, 149, 2005. Disponível em: http://www2.uol.com.br/vivermente/. Acesso em 22/07/05.

RING, B. P. Introduction to Personality Type and Personality. 1998 Disponível em: <http://members.tripod.com/ PersonalityInstitute/ TypeTerminology.htm $>$. Acesso em: 26/08/03.

SABBATINI, R. M. E. Acupuntura Funciona? 2003. Disponível em: $<$ http://www://epub.org.br/svol/artigo86.htm>. Acesso em 22/ $\underline{06 / 03 .}$

SO, D. W. Acupuncture Outcomes, Expectations, Patient-Provider Relationship, and the Placebo Effect: Implications for Health Promotion. American Journal of Public Health, 92(10), 2002, pp.1662-1667. (Washington)

STEINER, R. Os Temperamentos: suas Características, suas Causas, seu Tratamento. Ribeirão Preto, SP: Convívio, 1990.

WANG, S., \& KAIN, Z. N. Auricular Acupuncture: a Potential Treatment for Anxiety. Anesthesia \& Analgesia, 92(2), 2001, pp.548553.

WHITE, K. P. Psychology and Complementary and Alternative Medicine. Professional Psychology: Research and Practice, 31(6), 2000, pp.671-681.

WHITE, A. Neurofisiolologia da Analgesia por Acupuntura. In Ernst, E.; White, A. Acupuntura: uma Avaliação Científica. SP: Manole, 2001.

YANG, X.; LIU, X.; LUO, H.; JIA, Y. Clinical Observation of Needling Extrachannel Points in Treating Mental Depression. Journal of Traditional Chinese Medicine, 14, 1994, pp.14-18. (Beijing). 